\title{
Molecular Epidemiology and Genetic Diversity of Zika Virus from Field-Caught Mosquitoes in Various Regions of Thailand
}

\author{
Atchara Phumee ${ }^{1,2}$, Rome Buathong ${ }^{3}$, Rungfar Boonserm ${ }^{2}$, Proawpilart Intayot ${ }^{4}$, \\ Nucharat Aungsananta ${ }^{5}$, Akanitt Jittmittraphap ${ }^{6}$, Yutthana Joyjinda ${ }^{1}$, \\ Supaporn Wacharapluesadee ${ }^{1}$ and Padet Siriyasatien ${ }^{2, *}$ \\ 1 Thai Red Cross Emerging Infectious Diseases-Health Science Centre, World Health Organization \\ Collaborating Centre for Research and Training on Viral Zoonoses, Chulalongkorn Hospital, Faculty of \\ Medicine, Chulalongkorn University, Bangkok 10330, Thailand; amphumee@gmail.com (A.P.); \\ yutthana.jjd@gmail.com (Y.J.); spwa@hotmail.com (S.W.) \\ 2 Vector Biology and Vector Borne Disease Research Unit, Department of Parasitology, Faculty of Medicine, \\ Chulalongkorn University, Bangkok 10330, Thailand; sky_rung123@hotmail.com \\ 3 Bureau of Epidemiology, Department of Disease Control, Ministry of Public Health, Nonthaburi 11000, \\ Thailand; romebua@hotmail.com \\ 4 Medical Science Program, Faculty of Medicine, Chulalongkorn University, Bangkok 10330, Thailand; \\ khunproaw@gmail.com \\ 5 Public Health Center 22 Wat Pak Bor, Health Department, Bangkok Metropolitan Administration, Bangkok \\ 10250, Thailand; thephonee@gmail.com \\ 6 Department of Microbiology and Immunology, Faculty of Tropical Medicine, Mahidol University, Bangkok \\ 10400, Thailand; akanitt@hotmail.com \\ * Correspondence: padet.s@chula.ac.th
}

Received: 15 January 2019; Accepted: 1 March 2019; Published: 6 March 2019

\begin{abstract}
Zika virus (ZIKV) infection is an emerging and re-emerging arbovirus disease that is transmitted to humans through the bite of infected mosquitoes. ZIKV infections were first described in Thailand in 1954 from the sera of indigenous residents and several travelers returning from Thailand in 2014. However, reported cases in Thailand have been increasing since 2015 and 2016, and epidemiological information about the vectors of ZIKV is unclear. We investigated the molecular epidemiology and genetic diversity of ZIKV from mosquitoes collected from different geographic regions experiencing ZIKV outbreaks in Thailand. Polymerase chain reaction was used to amplify the non-structural protein (NS5) gene of ZIKV, which was then sequenced. A total of 1026 mosquito samples (626 females, 367 males, and 33 larvae) were collected from active ZIKV patients' houses. ZIKV was detected in 79 samples (7.7\%), including Aedes aegypti (2.24\% female, $1.27 \%$ male, and $0.19 \%$ larvae), Culex quinquefasciatus (1.85\% female, $1.66 \%$ male, and $0.29 \%$ larvae), and Armigeres subalbatus ( $0.1 \%$ female and $0.1 \%$ male), whereas no ZIKV was detected in Aedes albopictus. Phylogenetic analysis of the 79 positive samples were classified into two clades: Those closely related to a previous report in Thailand, and those related to ZIKV found in the Americas. This is the first report of the detection of ZIKV in Ae. aegypti, Cx. quinquefasciatus, and Ar. subalbatus mosquitoes, and genetic variations of ZIKV in the mosquitoes collected from several geographic regions of Thailand were examined. Detection of ZIKV in male and larval mosquitoes suggests that vertical transmission of ZIKV occurred in these mosquito species. This study provides a more in-depth understanding of the patterns and epidemiologic data of ZIKV in Thailand; the data could be used for future development of more effective prevention and control strategies of ZIKV in Thailand.
\end{abstract}

Keywords: Zika virus; mosquitoes; molecular epidemiology; genetic diversity; Thailand 


\section{Introduction}

The Zika virus (ZIKV) is a mosquito-borne flavivirus, closely related to dengue, Japanese encephalitis, West Nile, and yellow fever viruses [1]. ZIKV is transmitted primarily by Aedes mosquitoes. ZIKV is classified into African and Asian lineages [2,3]. In 1947, ZIKV was first found in a forest in Uganda in rhesus macaque monkeys. ZIKV was first isolated from an Aedes africanus mosquito collected at the same site [4] and documented in humans in 1952 from Uganda and the United Republic of Tanzania [5]. In 1966, ZIKV was first isolated in Asia from Ae. aegypti mosquitoes collected in Malaysia [6]. In Thailand, ZIKV infections were first described in 1954 in the sera of autochthonous residents using neutralizing antibodies against ZIKV [7]. There are some reports of ZIKV cases among Canadian [8], German [9], and Japanese [10] travelers returning from Thailand in 2014. Buathong et al. [11] described seven autochthonous acute ZIKV infections cases from the Ratchaburi, Phetchabun, Sisaket, and Lamphun provinces, confirmed by molecular or serological testing. The phylogenetic tree showed that these ZIKV belonged to the Asian lineage. During January to November 2016, a total of 686 Zika infection cases were reported in Thailand by the Ministry of Public Health (MoPH) [12]. The MoPH reported the first two indigenous cases of ZIKV-related microcephaly in Asia since September 2016 [13]. Although human ZIKV infection cases had been reported, data are lacking on ZIKV in mosquito vectors in Thailand. Many studies reported that Aedes mosquitoes such as Ae. africanus, Ae. aegypti, Ae. apicocoargenteus, Ae. furcifer, Ae. vitattus, and Ae. luteocephalus are the principle vectors of ZIKV in Africa [14-17]. In Southeastern Senegal, several mosquito species are probable potential vectors for ZIKV transmission, including Ae. aegypti, Ae. africanus, Ae. furcifer, Ae. luteocephalus, Ae. vittatus, Ae. taylori, Ae. dalzieli, Ae. hirsutus, Ae. metallicus, Ae. unilinaetus, Culex perfuscus, Mansonia uniformis, and Anopheles coustani [18]. In Southeast Asia, potential vectors of ZIKV transmission include Ae. aegypti [19] and Ae. albopictus [20]. Our previous studies found that Ae. aegypti and Armigeres sulalbatus are naturally infected with ZIKV in Thailand [21]. All the reports indicated that ZIKV infection is emerging, re-emerging, and increasing in many different areas, in addition to the discovery of many mosquito species naturally infected with ZIKV. Therefore, finding naturally ZIKV infected mosquitoes is essential for understanding the epidemiology of ZIKV infection. In this study, we investigated the potential vectors, molecular epidemiology, and genetic diversity of ZIKV in mosquitoes from several affected regions in Thailand by using Hemi-nested real-time polymerase chain reaction (hn-RT-PCR) of the non-structural protein (NS5) gene. Information obtained from the study can be applied to develop effective control strategies for ZIKV infection in Thailand. The nucleotide sequence data also provide fundamental information for the application of molecular techniques for future development.

\section{Results}

\subsection{ZIKV Infection in Mosquitoes}

A total of 1026 mosquito samples were collected in the 31 provinces of six regions in affected areas in 2016, including 626 females, 367 males, and 33 larvae. Positive samples were found in 15 provinces, of which most were found in the central region (Figure 1). ZIKV RNA was detected in 7.7\% (79/1026) of mosquitoes, of which $4.19 \%$ positive samples were found in female, $3.03 \%$ in male, and $0.48 \%$ in larval mosquitoes. Mosquitoes infected with ZIKV were found in Ae. aegypti (2.24\% female, $1.27 \%$ male, and $0.19 \%$ larva), $C x$. quinquefasciatus ( $1.85 \%$ female, $1.66 \%$ male, and $0.29 \%$ larva) and $A r$. subalbatus ( $0.1 \%$ female and $0.1 \%$ male) (Figure 2), whereas we were unable to detect ZIKV RNA in $A$ e. albopictus. The ZIKV sequences showed $98-100 \%$ sequence identity with the partial NS5 genes of ZIKV available in the GenBank database. For the first time, we detected ZIKV RNA in Cx. quinquefasciatus among female, male, and larvae in Thailand. We think that Ae. aegypti, Cx. quinquefasciatus, and $A r$. subalbatus should be considered vectors of ZIKV infection in Thailand. 


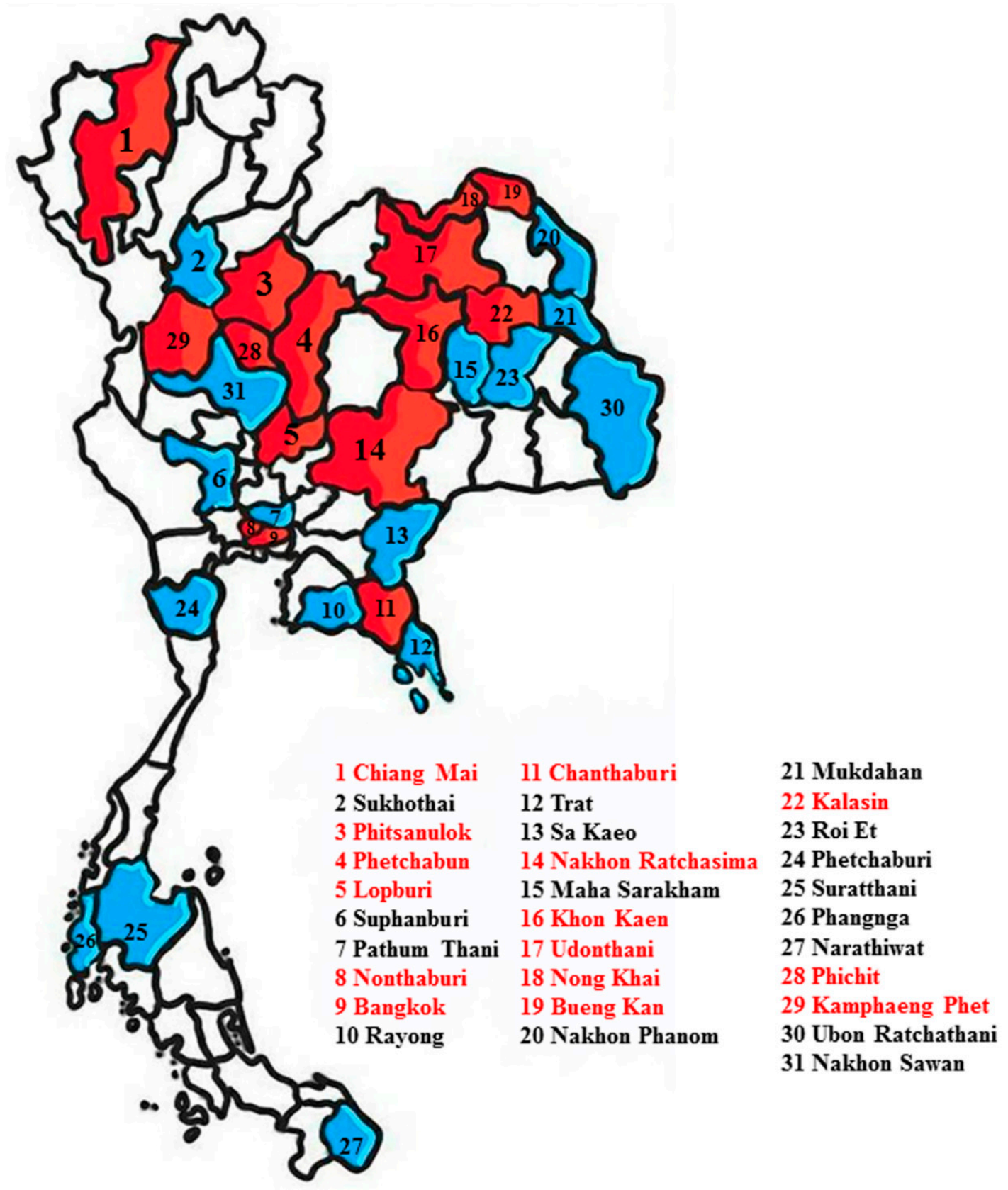

Figure 1. Map of Thailand showing locations of the sample-collection sites in the 31 provinces of 6 regions in affected areas. Red denotes the collection locations of positive Zika virus (ZIKV) in mosquitoes and blue denotes negative ZIKV in mosquitoes. 


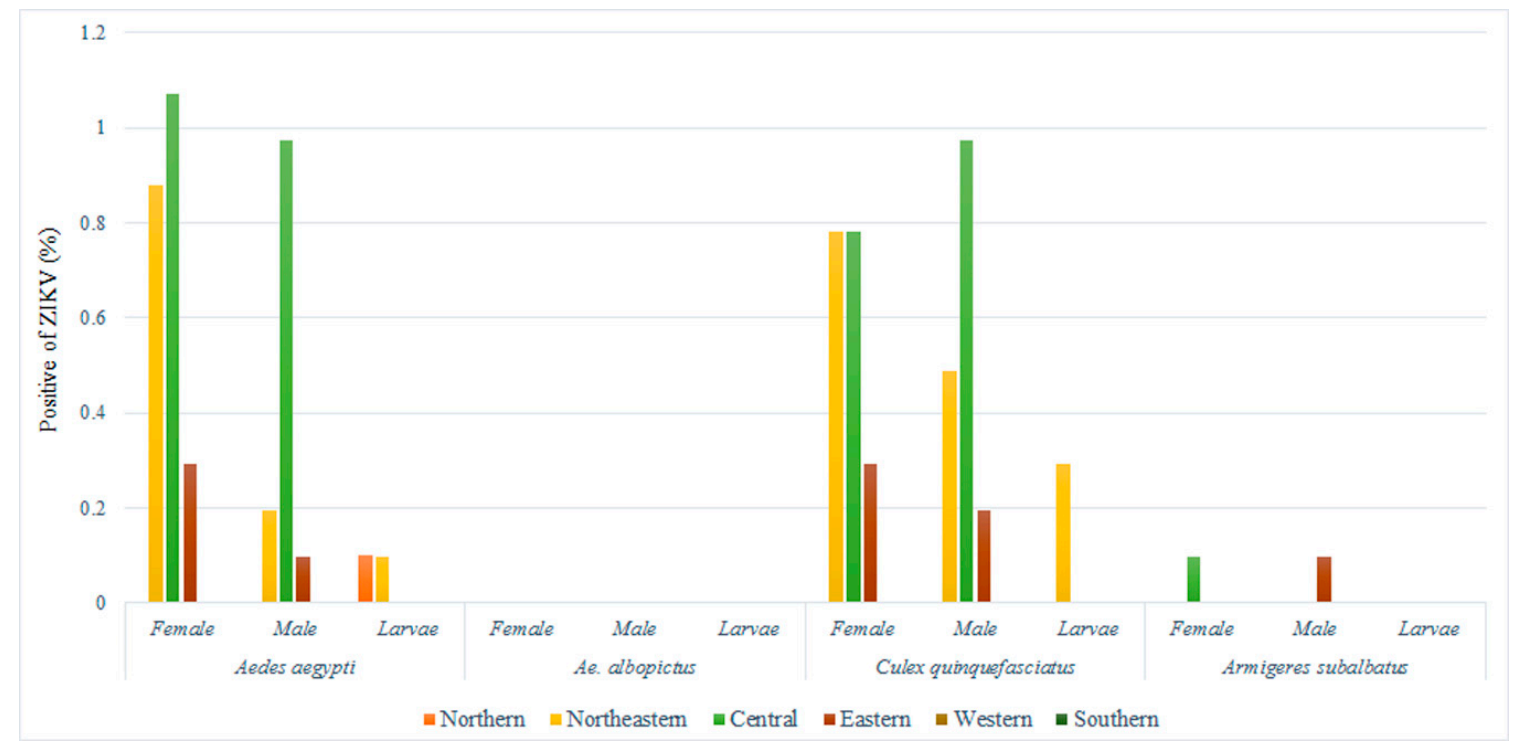

Figure 2. Distribution of ZIKV infection for each area of endemicity.

\subsection{Sequencing and Phylogenetic Analysis}

The 79 sequences, when compared with the GenBank database, were similar to ZIKV and showed the clade to be within the Asian lineage. The nucleotide sequences of NS5 of ZIKV were submitted to the GenBank database, accession numbers MK271800-MK271878. We report the genetic variations in ZIKV from mosquitoes collected from several geographic regions. The ZIKV from mosquitoes in this study can be classified into two clades: The Asian clades from Chiang Mai, Nong Khai, Phitsanulok, and Phetchabun, closely related to a previous report in Thailand [22,23]; and the American clade related to ZIKV found in the Americas (Figure 3). The intraspecific variation analysis between the Asian and the American clade showed 1-6\% variation. For the interspecific variation in this study, the Asian lineage showed 15-19\% variation from the African lineage. Sequences of ZIKV obtained from adults and larvae of same mosquito species were compared. Some adults and larvae were $100 \%$ identical and some showed differences in ZIKV sequences between adults and larvae of the same mosquito species (Figure 4). 


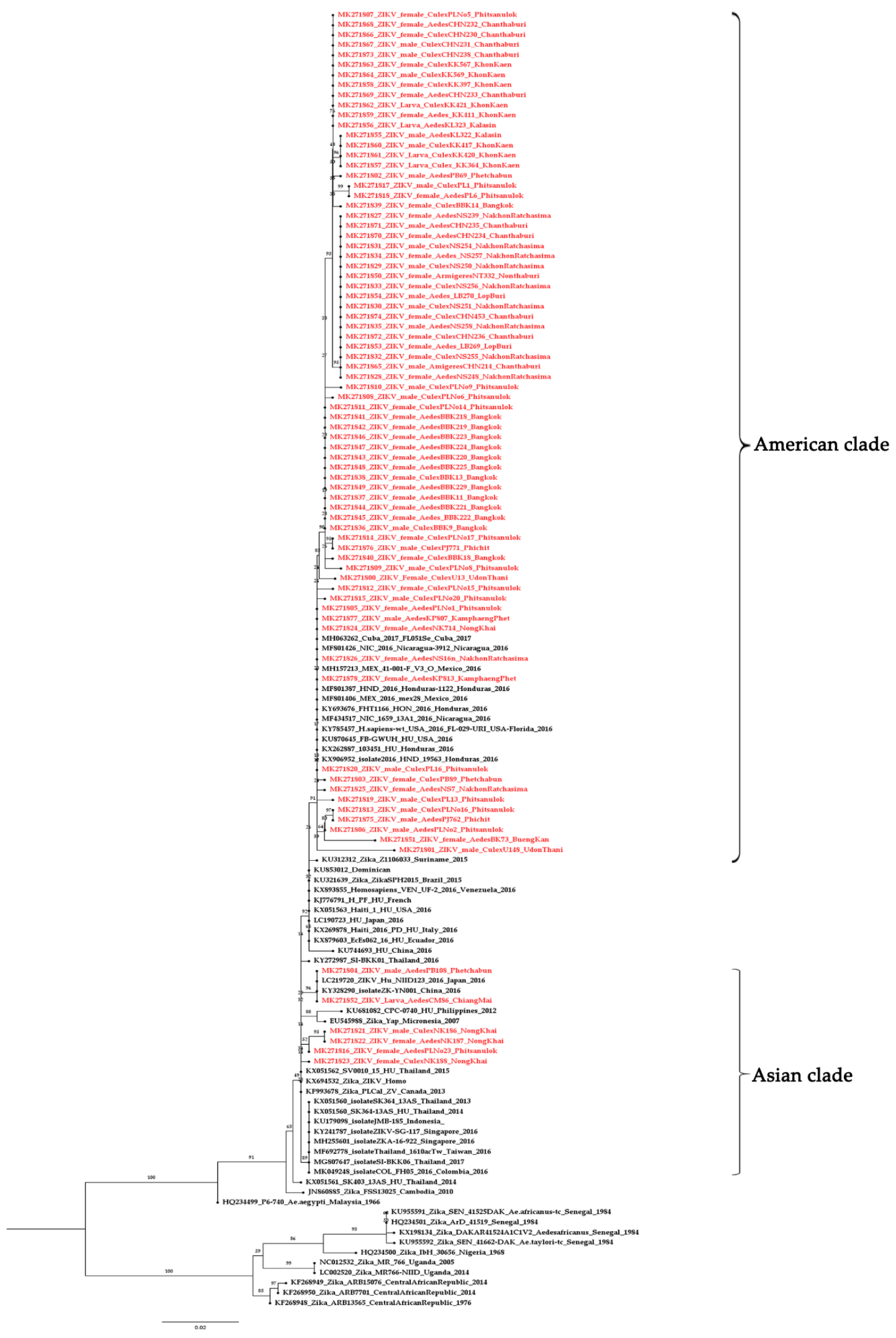

Figure 3. Phylogenetic tree of ZIKV mosquitoes constructed from partial NS5 sequences from all region of Thailand. The maximum likelihood was constructed with IQ-TREE by using the maximum-likelihood method with 1000 ultrafast bootstrap replicates. The best-fit model of substitution was found using the auto function on the IQ-TREE web server. The sequences from this study are indicated with a red color. 

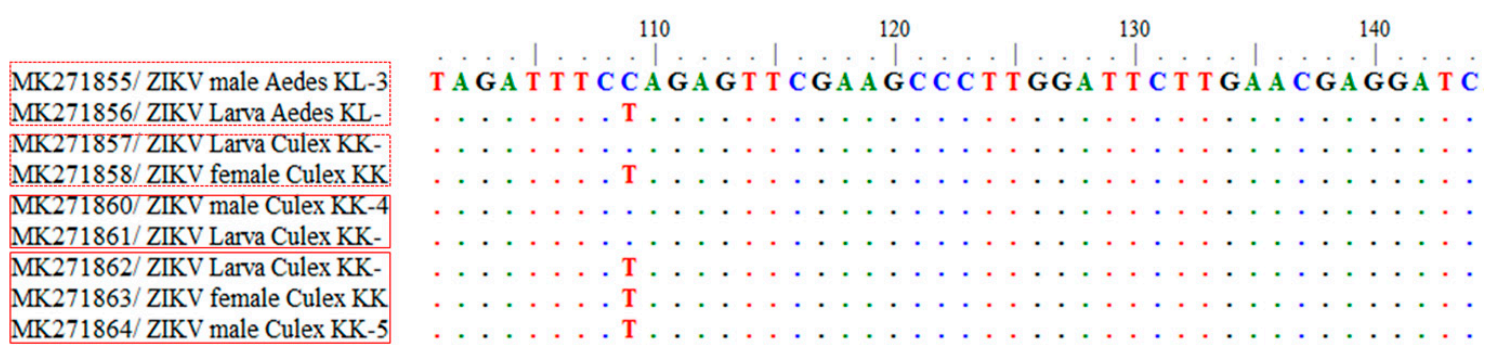

Figure 4. Comparison between sequences of ZIKV obtained from different mosquito stages.

\section{Discussion}

To the best of our knowledge, few studies have investigated the genetic diversity of ZIKV in Ae. aegypti, Cx. quinquefasciatus, Ae. albopictus, and Ar. subalbatus, which are commonly found in anthropized tropical and subtropical areas, especially in Thailand. Since 2016, reported cases of ZIKV in Thailand have increased. With no vaccine or specific treatment, the major approach to prevention and control of ZIKV infection is vector control [24]. A previous report suggested that virus transmission depends on the mosquito species, geographic location, and virus type [4]. Thus, study of the molecular epidemiology and genetic diversity of ZIKV from mosquitoes in different geographic regions in Thailand is necessary. In this study, we conducted a molecular epidemiologic and phylogenetic analysis of ZIKV in six regions of Thailand in 2016. The results provide an overview of the genetic diversity of ZIKV in epidemic regions. Of the collected mosquitoes, $7.7 \%$ of female, male, and larval mosquitoes were positive for ZIKV in Ae. aegypti, Cx. quinquefasciatus, and in both female and male Ar. subalbatus; whereas ZIKV RNA was not detected Ae. albopictus. However, some Ae. aegypti and $C x$. quinquefasciatus contained blood meals, and the positive ZIKV RNA from these samples may have caused an overestimation of the virus infection rate in mosquitoes if the mosquitoes fed on a person's blood that contained ZIKV. The literature shows that the ZIKV isolated from genus Culex, Anopheles or Mansonia suggests the potential role of these mosquitoes as secondary vectors in ZIKV transmission [25]. However, other findings showed that ZIKV may have a wider range of vectors through both vector competence assay and field studies with natural ZIKV infection [22]. For example, Ae. aegypti and Ae. albopictus were capable of transmitting ZIKV in a vector competence assay and through natural infection [20,26-28]. An. coustani [18] and An. gambiae [29] were naturally infected with ZIKV and are probable vectors in Senegal. Several reports showed that $C x$. quinquefasciatus is a potential ZIKV transmission vector and that ZIKV can replicate in Cx. quinquefasciatus. [30,31].

Our report is the first in Thailand that detected ZIKV RNA in different developmental stages (larva and male and female adults) of $C x$. quinquefasciatus. Our results support that transovarian transmission of ZIKV occurs in Ae. aegypti and Cx. quinquefasciatus mosquitoes in the field. In contrast, $C x$. torrentium and $C x$. molestus from Germany [32], as well as $C x$. sitiens and $C x$. annulirostris from Australia [33,34], were not susceptible to ZIKV. Cx. pipiens from Italy [35], Tunisia [36], Germany [32], and the U.S. [37] were not infected when exposed to ZIKV through an artificial blood meal. Our results indicate that $C x$. quinquefasciatus could be another potential vector for ZIKV transmission in Thailand. The reason we did not find ZIKV in Ae. albopictus is that Ae. albopictus displays exophagic and exophilic behavior. The mosquitoes prefer to feed outside houses, and after feeding, they rest outside houses, especially in the tree crop such palm trees, rubber plantation. However, in this study, we collected mosquitoes in and around houses. This why the number of Ae. albopictus collected in this study was low, so additional studies on Ae. albopictus and ZIKV in Thailand should be completed in the future. Further studies are required to investigate additional geographical areas using a larger sample size of mosquitoes.

We investigated the phylogenetic relationships of 79 of the sequences of NS5-ZIKV in mosquitoes using the maximum likelihood (ML) mapping method with 1000 replicates. NS5 is essential for the replication of the flaviviral RNA genome [38-40]. Two major lineages (African and Asian) of ZIKV 
were identified using NS5-RT-PCR [41]. The 79 positive samples showed that the ZIKV in this study belongs to the Asian lineage (Asian clade and American clade). The ZIKV found in mosquitoes collected from the same area were classified into the same clade, such as Bangkok (MK271836-271849). The Asian clade was detected in both Aedes and Culex in the adult and larval stages. However, in some areas such as Phitsanulok, ZIKV was found both Asian and American clade in Aedes mosquitoes. We were interested in exploring differences in ZIKV from mosquitoes that were classified into the two clades. Our phylogenetic analysis revealed numerous sequence variations (15-19\%) of ZIKV mosquitoes between the African and Asian lineages, as well as among different regions (1-6\%) within the Asian lineage. NS5 could be used for classification and determination of the genetic variations in ZIKV, and our report provides fundamental data for further epidemiological studies of ZIKV in Thailand. A report by Lanciotti et al. (2016) [42] demonstrated that ZIKV obtained from Guatemala and Puerto Rico are all within the Asian lineage and most closely related to ZIKV isolation from Brazil (2015) and French Polynesia (2013). They assumed that it is possible that Asian lineage viruses may have been evolving and spreading geographically throughout Asia and the Pacific Islands since at least 1966 [43] as well as having probably occurred through the travel or living of people in endemic areas. This can explain why we found American-clade ZIKV in our study. However, little information is available about the molecular epidemiology, evolution, and ecology of ZIKV. Our findings therefore suggest that it is likely that the genetic diversity of ZIKV is underestimated due to the limited sequence data currently available for humans in Thailand. Therefore, extensive surveys and more precise studies of ZIKV infection in patients covering more areas and larger sample sizes must be performed in order to understand geographic location and virus type interaction. In this study, we detected ZIKV RNA in whole mosquitoes, so the role of $C x$. quinquefasciatus and Ar. subalbatus for ZIKV transmission should be investigated. ZIKV transmission in expectorated saliva of $C x$. quinquefasciatus and Ar. subalbatus should be studied to obtaining more accurate information. The vector control strategies for ZIKV outbreaks should focus on other mosquito species, and the larval control measures should focus on the breeding sites of $C x$. quinquefasciatus and Ar. subalbatus.

\section{Materials and Methods}

\subsection{Ethics Statement}

The study was approved by the animal research ethics committee of Chulalongkorn University Animal Care and Use Protocol (CU-ACUP), Faculty of Medicine, Chulalongkorn University, Bangkok, Thailand (COA No. 023/2560).

\subsection{Sample Collection}

A total of 1026 larval or adult mosquitoes were collected from active ZIKV infected patients' homes in 2016. The collections were conducted in different geographical regions of Thailand, including the northern (Chiang Mai), north-eastern (Bueng Kan, Kalasin, Khon Kaen, Nakhon Ratchasima, Mukdahan, Maha Sarakham, Udon Thani, Nong Khai, Roi Et, Ubon Ratchathani, and Nakhon Phanom), central (Bangkok, Kamphaeng Phet, Lop Buri, Nonthaburi, Phetchabun, Phitsanulok, Phichit, Nakhon Sawan, Sukhothai, Pathum Thani, and Suphan Buri), eastern (Chanthaburi, Rayong, Trat, and Sa Kaeo), western (Phetchaburi), and southern (Narathiwat, Phangnga and Surat Thani) regions. Mosquitoes were collected in and around houses of confirmed ZIKV infected patients using mosquito aspirators, and larvae were collected in and around houses of ZIKV infected patients using a large-mouth plastic dropper or a plastic cup. These samples were differentiated according to their sex and species based on morphological identification, separated into pools of 10 individuals, and kept in liquid nitrogen and transferred to the laboratory of Vector Biology and Vector Borne Disease Research Unit, Department of Parasitology, Faculty of Medicine, Chulalongkorn University for viral detection. Larvae were reared into adults and used for species identification and ZIKV detection. Individual mosquitoes were used for ZIKV detection. 


\subsection{Viral RNA Extraction}

All mosquito samples were ground in $1 \times$ phosphate buffered saline (PBS) and centrifuged at $11,000 \times g$ for $10 \mathrm{~min}$. The supernatant was used for viral RNA extraction by using a viral RNA extraction kit, Invisorb ${ }^{\circledR}$ Spin Virus RNA Mini kit (STRATEC molecular GmbH, Berlin, Germany) following the manufacturer's instructions. RNA concentration and purity were quantified by a Nano Drop 2000c spectrophotometer (Thermo Fisher Scientific, MA, USA). The extracted RNA samples were used for ZIKV detection immediately and the rest of samples were stored at $-80^{\circ} \mathrm{C}$.

\subsection{ZIKV RNA Detection}

The RNA samples extracted from the mosquitoes were amplified for detecting ZIKV at its NS5 gene by hemi-nested RT-PCR (hn-RT-PCR), following a process modified from Moureau et al. [44]. The hn-RT-PCR amplification reaction was set up in a final volume of $25 \mu \mathrm{L}$ using the Superscript III one-step RT-PCR kit (Invitrogen, Grand Island, NY, USA). The nested PCR was performed with $2 \mu \mathrm{L}$ from the first reaction using 1 unit of Taq DNA polymerase (Thermo Fisher Scientific, MA, USA). The PCR products were analyzed via $2 \%$ agarose gel electrophoresis, stained with ethidium bromide, and visualized with Quantity One Quantification Analysis Software Version 4.5.2 (Gel DocEQ System; Bio-Rad, Hercules, CA, USA). We constructed the lower band of synthesized positive control plasmid as a positive control to prevent the contamination of the samples.

\subsection{Gel Purification and Sequencing}

Positive PCR products were recovered from the gel and purified using an Agarose Gel DNA Purification Kit: Invisorb ${ }^{\circledR}$ Fragment CleanUp (STRATEC molecular GmbH, Berlin, Germany) following the manufacturer's instructions. The purified DNA was sent for direct DNA sequencing to 1st Base Laboratories. (Axil Scientific, Singapore). Nucleotide sequences were analyzed by comparison with the GenBank database using a BLAST program.

\subsection{Phylogenetic Tree Construction}

The sequences were aligned using BioEdit Sequence Alignment Editor Version 7.2.5 [45]. The phylogenetic trees were constructed using the maximum-likelihood method with IQ-TREE on the IQ-TREE web server (http:/ /iqtree.cibiv.univie.ac.at/) with 1000 ultrafast bootstrap replicates. The best-fit model of substitution was found using the auto function on the IQ-TREE web server [46]. The phylogenetic tree was finally viewed and edited with FigTree v1.4.4 software (http:/ / tree.bio.ed. ac.uk/software/figtree/). All sequences in this study were analyzed with 40 reference strains of Asian lineage (GenBank accession no. KX051560, MK049248, MG807647, MH255601, MF692778, KU179098, KY241787, LC219720, KY328290, HQ234499, KX051560, KX051561, KY272987, KX051562, MH157213, MF801406, MH063262, MF801426, MF434517, MF801387, KX906952, KY785457, KY693676, KX262887, KU681082, KU853012, KX879603, KU870645, KJ776791, KU744693, LC190723, KX051563, KX269878, KX893855, JN860885, EU545988, KF993678, KU312312, KX694532, and KU321639) and 10 reference strains from the African lineage (GenBank accession no. NC012532, LC002520, HQ234501, HQ234500, KF268949, KF268950, KF268948, KX198134, KU955591, and KU955592).

\section{Conclusions}

The current outbreak of ZIKV in Thailand is poorly understood. In this report, we demonstrated the use of molecular techniques for investigating the epidemiology and genetic diversity of ZIKV in mosquitoes collected from ZIKV outbreak areas in Thailand. ZIKV was detected in female, male, and larvae of Ae. aegypti and $C x$. quinquefasciatus, in female and male Ar. subalbatus, which might be vectors of ZIKV, and thus causative agents of ZIKV infection in Thailand. This study represents the first detection of ZIKV RNA in Cx. quinquefasciatus from Thailand. ZIKV from mosquitoes in Thailand can be divided into two clades that are closely related to those reported in a previous Thai study and 
another clade related to ZIKV from the Americas. However, extensive surveys and more precise studies of ZIKV infection in mosquitoes covering more areas and larger sample sizes must be performed to understand geographic location and virus interaction and to provide the basis for an effective vector control program. These actions are important keys to prevent the disease from spreading.

Author Contributions: Conceptualization, P.S. and A.P.; methodology, S.W.; Y.J. and P.I.; software, A.P.; validation, P.S. and A.P.; formal analysis, P.S.; investigation, R.B. (Rome Buathong); A.J. and N.A. resources, P.S.; data curation, P.S. and A.P; writing—original draft preparation, A.P.; writing—review and editing, P.S.; visualization, P.S.; supervision, P.S.; project administration, R.B. (Rungfar Boonserm); funding acquisition, P.S.

Funding: This study was supported by National Science and Technology Development Agency (Thailand) (Grant No. P-16-50702), the Research Chair Grant and National Research Council of Thailand, Health Systems Research Institute (Grant No. 61-003), Rachadapisaek Sompote Fund (Grant No. RA/MF 11/61), and the World Health Organization (WHO) and the United States Agency for International Development (USAID) grant.

Acknowledgments: We appreciated the staff of Department of disease control, Bureau of epidemiology, ministry of public health, Thailand. We would like to thank Sittiporn Parnmen for consulting the phylogenetic tree.

Conflicts of Interest: The authors declare no conflict of interest.

\section{References}

1. Weaver, S.C.; Costa, F.; Garcia-Blanco, M.A.; Ko, A.I.; Ribeiro, G.S.; Saade, G.; Shi, P.Y.; Vasilakis, N. Zika virus: History, emergence, biology, and prospects for control. Antivir. Res. 2016, 130, 69-80. [CrossRef] [PubMed]

2. Musso, D.; Gubler, D.J. Zika virus. Clin. Microbiol. Rev. 2016, 29, 487-524. [CrossRef] [PubMed]

3. Wang, A.; Thurmond, S.; Islas, L.; Hui, K.; Hai, R. Zika virus genome biology and molecular pathogenesis. Emerg. Microbes Infect. 2017, 6, e13. [CrossRef] [PubMed]

4. Plourde, A.R.; Bloch, E.M. A literature review of Zika virus. Emerg. Infect. Dis. 2016, 22, 1185-1192. [CrossRef] [PubMed]

5. Dick, G.W.; Kitchen, S.F.; Haddow, A.J. Zika virus. I. Isolations and serological specificity. Trans. R. Soc. Trop. Med. Hyg. 1952, 46, 509-520. [CrossRef]

6. Marchette, N.J.; Garcia, R.; Rudnick, A. Isolation of Zika virus from Aedes aegypti mosquitoes in Malaysia. Am. J. Trop. Med. Hyg. 1969, 18, 411-415. [CrossRef] [PubMed]

7. Pond, W.L. Arthropod-borne virus anti bodies in sera from residents of South-East Asia. Trans. R. Soc. Trop. Med. Hyg. 1963, 57, 364-371. [CrossRef]

8. Fonseca, K.; Meatherall, B.; Zarra, D.; Drebot, M.; MacDonald, J.; Pabbaraju, K.; Wong, S.; Webster, P.; Lindsay, R.; Tellier, R. First case of Zika virus infection in a returning Canadian traveler. Am. J. Trop. Med. Hyg. 2014, 91, 1035-1038. [CrossRef] [PubMed]

9. Tappe, D.; Rissland, J.; Gabriel, M.; Emmerich, P.; Gunther, S.; Held, G.; Smola, S.; Schmidt-Chanasit, J. First case of laboratory-confirmed Zika virus infection imported into Europe, November 2013. Eurosurveillance 2014, 19, 20685. [CrossRef] [PubMed]

10. Shinohara, K. Zika Virus-Japan ex Thailand. Available online: http:/ / www.promedmail.org (accessed on 8 January 2019).

11. Buathong, R.; Hermann, L.; Thaisomboonsuk, B.; Rutvisuttinunt, W.; Klungthong, C.; Chinnawirotpisan, P.; Manasatienkij, W.; Nisalak, A.; Fernandez, S.; Yoon, I.K.; et al. Detection of Zika virus infection in Thailand, 2012-2014. Am. J. Trop. Med. Hyg. 2015, 93, 380-383. [CrossRef] [PubMed]

12. ProMed-mail. PRO/MBDS > Zika virus-Thailand (09). Available online: https://www.promedmail.org/ post/4631824 (accessed on 4 May 2017).

13. World Health Organization (WHO). Emergencies: Situation report-Zika virus microcephaly Guillain-Barré syndrome. Available online: http:/ / www.who.int/emergencies/zika-virus/situation-report/6-october2016/en/ (accessed on 4 May 2017).

14. Haddow, A.J.; Williams, M.C.; Woodall, J.P.; Simpson, D.I.; Goma, L.K. Twelve isolations of Zika virus from Aedes (Stegomyia) africanus (Theobald) taken in and above a Uganda forest. Bull. World Health Organ. 1964, 31, 57-69. [PubMed]

15. Weinbren, M.P.; Williams, M.C. Zika virus: Further isolations in the Zika area, and some studies on the strains isolated. Trans. R. Soc. Trop. Med. Hyg. 1958, 52, 263-268. [CrossRef] 
16. Fagbami, A.H. Zika virus infections in Nigeria: Virological and seroepidemiological investigations in Oyo State. J. Hyg. 1979, 83, 213-219. [CrossRef] [PubMed]

17. McCrae, A.W.; Kirya, B.G. Yellow fever and Zika virus epizootics and enzootics in Uganda. Trans. R. Soc. Trop. Med. Hyg. 1982, 76, 552-562. [CrossRef]

18. Diallo, D.; Sall, A.A.; Diagne, C.T.; Faye, O.; Faye, O.; Ba, Y.; Hanley, K.A.; Buenemann, M.; Weaver, S.C.; Diallo, M. Zika virus emergence in mosquitoes in southeastern Senegal, 2011. PLoS ONE 2014, 9, e109442. [CrossRef] [PubMed]

19. Li, M.I.; Wong, P.S.; Ng, L.C.; Tan, C.H. Oral susceptibility of Singapore Aedes (Stegomyia) aegypti (Linnaeus) to Zika virus. PLoS Negl. Trop. Dis. 2012, 6, e1792. [CrossRef] [PubMed]

20. Wong, P.S.; Li, M.Z.; Chong, C.S.; Ng, L.C.; Tan, C.H. Aedes (Stegomyia) albopictus (Skuse): A potential vector of Zika virus in Singapore. PLoS Negl. Trop. Dis. 2013, 7, e2348. [CrossRef] [PubMed]

21. Tawatsin, A.; Phumee, A.; Thavara, U.; Sirisopa, P.; Ritthison, W.; Thammakosol, K.; Intayot, P.; Joyjinda, Y.; Wacharapluesadee, S.; Hemachudha, T.; et al. High infection rate of Zika virus in mosquitoes collected from an area of active Zika virus transmission of eastern Thailand. Thai. J. Vet. Med. 2018, 48, 551-558.

22. Ellison, D.W.; Ladner, J.T.; Buathong, R.; Alera, M.T.; Wiley, M.R.; Hermann, L.; Rutvisuttinunt, W.; Klungthong, C.; Chinnawirotpisan, P.; Manasatienkij, W.; et al. Complete genome sequences of Zika virus strains isolated from the blood of patients in Thailand in 2014 and the Philippines in 2012. Genome Announc. 2016, 4, e00359-16. [CrossRef] [PubMed]

23. Wongsurawat, T.; Athipanyasilp, N.; Jenjaroenpun, P.; Jun, S.; Kaewnapan, B.; Wassenaar, T.M.; Leelahakorn, N.; Angkasekwinai, N.; Kantakamalakul, W.; Ussery, D.W.; et al. Case of microcephaly after congenital infection with Asian lineage Zika virus, Thailand. Emerg. Infect. Dis. 2018, 24, 1758-1761. [CrossRef] [PubMed]

24. Possas, C. Zika: What we do and do not know based on the experiences of Brazil. Epidemiol. Health 2016, 38, e2016023. [CrossRef] [PubMed]

25. Epelboin, Y.; Talaga, S.; Epelboin, L.; Dusfour, I. Zika virus: An updated review of competent or naturally infected mosquitoes. PLoS. Negl. Trop. Dis. 2017, 11, e0005933. [CrossRef] [PubMed]

26. Chouin-Carneiro, T.; Vega-Rua, A.; Vazeille, M.; Yebakima, A.; Girod, R.; Goindin, D.; Dupont-Rouzeyrol, M.; Lourenço-de-Oliveira, R.; Failloux, A.B. Differential susceptibilities of Aedes aegypti and Aedes albopictus from the Americas to Zika virus. PLoS Negl. Trop. Dis. 2016, 10, e0004543. [CrossRef] [PubMed]

27. Richard, V.; Paoaafaite, T.; Cao-Lormeau, V.M. Vector competence of French Polynesian Aedes aegypti and Aedes polynesiensis for Zika virus. PLoS Negl. Trop. Dis. 2016, 10, e0005024. [CrossRef] [PubMed]

28. Grard, G.; Caron, M.; Mombo, I.M.; Nkoghe, D.; Mboui Ondo, S.; Jiolle, D.; Fontenille, D.; Paupy, C.; Leroy, E.M. Zika virus in Gabon (Central Africa) 2007: A new threat from Aedes albopictus? PLoS Negl. Trop. Dis. 2014, 8, e2681. [CrossRef] [PubMed]

29. Althouse, B.M.; Hanley, K.A.; Diallo, M.; Sall, A.A.; Ba, Y.; Faye, O.; Diallo, D.; Watts, D.M.; Weaver, S.C.; Cummings, D.A. Impact of climate and mosquito vector abundance on sylvatic arbovirus circulation dynamics in Senegal. Am. J. Trop. Med. Hyg. 2015, 92, 88-97. [CrossRef] [PubMed]

30. Guedes, D.R.; Paiva, M.H.; Donato, M.M.; Barbosa, P.P.; Krokovsky, L.; Rocha, S.W.D.S.; Saraiva, K.; Crespo, M.M.; Rezende, T.M.; Wallau, G.L.; et al. Zika virus replication in the mosquito Culex quinquefasciatus in Brazil. Emerg. Microbes Infect. 2017, 6, e69. [CrossRef] [PubMed]

31. Guo, X.X.; Li, C.X.; Deng, Y.Q.; Xing, D.; Liu, Q.M.; Wu, Q.; Sun, A.J.; Dong, Y.D.; Cao, W.C.; Qin, C.F.; et al. Culex pipiens quinquefasciatus: A potential vector to transmit Zika virus. Emerg. Microbes Infect. 2016, 5, e102. [CrossRef] [PubMed]

32. Heitmann, A.; Jansen, S.; LuÈhken, R.; Leggewie, M.; Badusche, M.; Pluskota, B.; Becker, N.; Vapalahti, O.; Schmidt-Chanasit, J.; Tannich, E. Experimental transmission of Zika virus by mosquitoes from central Europe. Eurosurveillance 2017, 22, 30437. [CrossRef] [PubMed]

33. Hall-Mendelin, S.; Pyke, A.T.; Moore, P.R.; Mackay, I.M.; McMahon, J.L.; Ritchie, S.A.; Taylor, C.T.; Moore, F.A.; van den Hurk, A.F. Assessment of local mosquito species incriminates Aedes aegypti as the potential vector of Zika virus in Australia. PLoS Negl. Trop. Dis. 2016, 10, e0004959. [CrossRef] [PubMed]

34. Duchemin, J.B.; Mee, P.T.; Lynch, S.E.; Vedururu, R.; Trinidad, L.; Paradkar, P. Zika vector transmission risk in temperate Australia: A vector competence study. Virol. J. 2017, 14, 108. [CrossRef] [PubMed] 
35. Boccolini, D.; Toma, L.; Di Luca, M.; Severini, F.; Romi, R.; Remoli, M.E.; Sabbatucci, M.; Venturi, G.; Rezza, G.; Fortuna, C. Experimental investigation of the susceptibility of Italian Culex pipiens mosquitoes to Zika virus infection. Eurosurveillance 2016, 21, 30328. [CrossRef] [PubMed]

36. Amraoui, F.; Atyame-Nten, C.; Vega-RuÂa, A.; LourencËo-de-Oliveira, R.; Vazeille, M.; Failloux, A.B. Culex mosquitoes are experimentally unable to transmit Zika virus. Eurosurveillance 2016, 21, 30333. [CrossRef] [PubMed]

37. Weger-Lucarelli, J.; RuÈckert, C.; Chotiwan, N.; Nguyen, C.; Garcia Luna, S.M.; Fauver, J.R.; Foy, B.D.; Perera, R.; Black, W.C.; Kading, R.C.; et al. Vector competence of American mosquitoes for three strains of Zika virus. PLoS Negl. Trop. Dis. 2016, 10, e0005101. [CrossRef] [PubMed]

38. Egloff, M.P.; Bernarroch, D.; Selisko, B.; Romette, J.L.; Canard, B. An RNA cap (nucleoside-20-O)methyltransferase in the flavivirus RNA polymerase NS5: Crystal structure and functional characterization. EMBO J. 2002, 21, 2757-2768. [CrossRef] [PubMed]

39. Zou, G.; Chen, Y.L.; Dong, H.; Lim, C.C.; Yap, L.J.; Yau, Y.H.; Shochat, S.G.; Lescar, J.; Shi, P.Y. Functional analysis of two cavities in flavivirus NS5 polymerase. J. Biol. Chem. 2011, 286, 14362-14372. [CrossRef] [PubMed]

40. Kuno, G.; Chang, G.J.; Tsuchiya, K.R.; Karabatsos, N.; Cropp, C.B. Phylogeny of the genus Flavivirus. J. Virol. 1998, 72, 73-83. [PubMed]

41. Adiga, R. Phylogenetic analysis of the NS5 gene of Zika virus. J. Med. Virol. 2016, 88, 1821-1826. [CrossRef] [PubMed]

42. Lanciotti, R.; Lambert, A.J.; Holodniy, M.; Saavedra, S.; Signor, L. Phylogeny of Zika virus in western hemisphere, 2015. Emerg. Infect. Dis. 2016, 22, 933-935. [CrossRef] [PubMed]

43. Haddow, A.D.; Schuh, A.J.; Yasuda, C.Y.; Kasper, M.R.; Heang, V.; Huy, R. Genetic characterization of Zika virus strains: Geographic expansion of the Asian lineage. PLoS Negl. Trop. Dis. 2012, 6, e1477. [CrossRef] [PubMed]

44. Moureau, G.; Temmam, S.; Gonzalez, J.P.; Charrel, R.N.; Grard, G.; de Lamballerie, X. A real-time RT-PCR method for the universal detection and identification of flaviviruses. Vector Borne Zoonotic Dis. 2007, 7, 467-477. [CrossRef] [PubMed]

45. Hall, T.A. BioEdit: A user-friendly biological sequence alignment editor and analysis program for Windows 95/98/NT. Nucleic Acids Symp. Ser. 1999, 41, 95-98.

46. Trifinopoulos, J.; Nguyen, L.T.; von Haeseler, A.; Minh, B.Q. W-IQ-TREE: A fast online phylogenetic tool for maximum likelihood analysis. Nucleic Acids Res. 2016, 44, W232-W235. [CrossRef] [PubMed] 